\title{
AVALIAÇÃO DE ATRATIVOS ALIMENTARES UTILIZADOS NO MONITORAMENTO DE MOSCA-DAS-FRUTAS EM PESSEGUEIRO NA LAPA - PR ${ }^{1}$
}

\author{
LINO BITTENCOURT MONTEIRO², LOUISE LARISSAMAY DE MIO², ANTÔNIO CARLOS VARGAS MOTTA \\ BEATRIZMONTE SERRAT ${ }^{3}$, FRANCINELORENACUQUEL ${ }^{2}$
}

\begin{abstract}
RESUMO - As moscas-das-frutas do gênero Anastrepha são uma praga-chave na cultura do pessegueiro no Paraná. Atrativos alimentares foram testados para determinar a sua eficiência no monitoramento de moscas-das-frutas capturadas em frascos caçamoscas McPhail. O experimento foi conduzido por três anos, sendo que, em 2002, foram testados como atrativo o suco de uva da marca Maguari ${ }^{\circledR}$, o hidrolisado enzimático de proteína da marca BioAnastrepha® e o vinagre da marca Chemin Agrin ${ }^{\circledR}$. Nos dois anos seguintes, o vinagre foi substituído pelo composto protéico hidrolisável da marca Torula®. As substâncias atrativas à base de proteína foram as mais eficientes na captura de Anastrepha spp., e as capturas ocorreram antecipadas em relação ao suco de uva. De acordo com os resultados, recomendam-se atrativos à base de proteína para monitoramento de Anastrepha spp em pessegueiro, na Lapa.
\end{abstract}

Termo para indexação: Anastrepha, atrativo, monitoramento, pêssego.

\section{FOOD ATTRACTANTS USED IN THE MONITORING OF FRUIT FLIES IN PEACH TREES IN LAPA, PARANÁ (PR), BRAZIL}

\begin{abstract}
Fruit flies of Anastrepha genus are a key pest in peach trees in Paraná. Food attractants were tested to determine their efficiency in monitoring fruit flies captured in McPhail fly traps. The experiment was conducted over a period of three years. In 2002 the following attractors were tested: Maguari ${ }^{\circledR}$ brand grape juice, BioAnastrepha ${ }^{\circledR}$ brand hydrolyzed enzymatic protein and Chemin Agrin ${ }^{\circledR}$ vinegar. Over the next two years, the vinegar was replaced by Torula ${ }^{\circledR}$ hydrolyzed protein compound. Protein-based attractants were the most efficient in trapping Anastrepha spp. and captured flies earlier comparing to grape juice. According to the results, the use of protein-based attractants for monitoring Anastrepha spp in the Lapa peach trees was recommended.
\end{abstract}

Index terms: Anastrepha, food attractant, monitoring, peach

\section{INTRODUÇÃO}

O pessegueiro é cultivado no Sul do Brasil em uma área estimada em 30 mil ha. Normalmente, os pomares são formados com o plantio de várias espécies de fruteiras, tais como, ameixeira, caquizeiro, nectarina e pereira (Kovaleski et al., 2000). Esse complexo faz com que as fruteiras se constituam em plantas hospedeiras de pragas, possibilitando a sucessão de várias gerações no ano, tal como ocorre com as moscas-das-frutas, Anastrepha spp. (Diptera: Tephritidae). O gênero Anastrepha contém 193 espécies (Zucchi, 2000), das quais 94 ocorrem no Brasil. Entre as espécies que incidem sobre o pessegueiro, essas são as pragas mais importantes para o cultivo.

O controle das moscas-das-frutas é realizado com a pulverização de inseticidas, muitas vezes de forma intensa, o que pode provocar poluição ambiental e comprometer a saúde humana. Atualmente, há uma preocupação mundial em reduzir o uso de produtos fitossanitários, de modo que a produção de alimentos seja feita dentro de padrões mais ecológicos, seguindo as normas da produção integrada (Fachinello et al., 2003). Nessas condições, segundo Monteiro \& Hickel (2004), as pulverizações devem ser realizadas mediante um trabalho prévio de mensuração da população de moscas-das-frutas e do seu potencial em causar danos. O monitoramento é uma ferramenta utilizada para mensurar a população dos insetos, sendo que, para moscas-das-frutas, são empregados frascos caça-moscas McPhail com atrativos alimentares.

Os atrativos alimentares utilizados no monitoramento são sucos de frutas, melaço e vinagre. No Rio Grande do Sul e Santa Catarina, a recomendação é o uso de suco de uva para monitoramento de Anastrepha em macieira e pessegueiro (Salles, 1991; Hickel, 1993; Salles, 1995). Em São Paulo, usa-se o hidrolisado enzimático de proteína para o monitoramento de moscas-dasfrutas em citros, sendo o mesmo recomendado para outras fruteiras (Nascimento et al., 2000). Entre essas opções de atrativos, pode existir alguma que se sobressaia na atratividade a moscasdas-frutas e proporcione melhor eficiência de captura, dependendo do agroecossistema.

Dessa forma, o objetivo deste estudo foi determinar a eficiência de atrativos alimentares sobre a captura de Anastrepha

1 (Trabalho 042-2006). Recebido em 13-04-2006. Aceito para publicação em 18-10-2006. Estudo faz parte do programa de Produção Integrada de Pêssego, Ministério da Agricultura, Pecuária e Abastecimento, Brasília-DF.

${ }^{2}$ Eng. Agr., Doutor, Professor do Departamento de Fitotecnica e Fitossanidade da Universidade Federal do Paraná, Caixa Postal 19061, 81831-990, Curitiba-PR. E-mail:1bmonteiro@terra.com.br

${ }^{3}$ Eng. Agr., Doutor, Professor do Departamento de Solos e Engenharia Agrícola da Universidade Federal do Paraná 
spp., quando utilizados no monitoramento com frascos caçamoscas na cultura do pessegueiro, no município da Lapa-PR.

\section{MATERIAL E MÉTODOS}

Para determinar a eficiência dos atrativos alimentares na captura de moscas-das-frutas, foi instalado um experimento em pomar de pessegueiro na Fazenda Alvorada, no município da Lapa-PR, delimitado por mato nativo (vestígio da Mata Atlântica), em dois lados e campo nativo nos outros dois. Do total do pomar, foi selecionada uma parcela do pomar de 1 ha de pessegueiro 'Coral II', com 6 anos de idade, plantado no espaçamento de 6 x 3 $\mathrm{m}$ e conduzido no sistema de taça. Nove frascos caça-moscas McPhail de 500ml foram distribuídos nas plantas, em delineamento inteiramente casualisado, com três repetições, distanciados de 30 metros em cada bloco.

As substâncias atrativas avaliadas foram: suco de uva comercial, marca Maguari, diluído a 25\%; hidrolisado enzimático de proteína, subproduto da refinaria de milho, marca Bio Anastrepha (5\%), contendo bórax ( $\mathrm{pH}$ entre 8,5 e 9,0), e vinagre fermentado acético de álcool e vinho, da marca Chemim Agrin, diluído a 25\%. Em 2003 e 2004, o vinagre foi substituído por um composto protéico hidrolisável, marca Torula, na concentração de três tabletes, em 500ml de água, em função da baixa atratividade do vinagre no primeiro ano. O suco de uva e o vinagre foram trocados a cada sete dias, enquanto os atrativos à base de proteína foram substituídos a cada 15 dias.

O monitoramento foi executado pela contagem das moscas-das-frutas capturadas em caça-moscas de setembro a fevereiro em 2002 e 2003, e em 2004 limitou-se até dezembro. As avaliações foram realizadas nas segundas e quintas-feiras, retirando-se as moscas-das-frutas e completando-se os $400 \mathrm{ml} \mathrm{de}$ solução atrativa por frasco. As moscas-das-frutas foram guardadas em vidros para futuras identificações.

Os dados de captura foram transformados em raiz quadrada de $x+0,5$; os contrastes entre as médias dos tratamentos e dos anos de monitoramento foram comparados pelo teste de Tukey $(\mathrm{P}<0,05)$. Os atrativos que proporcionaram as maiores capturas de indivíduos no período de monitoramento foram então considerados os mais eficientes e definidos para recomendação de monitoramento da mosca-das-frutas na Lapa-PR.

\section{RESULTADOS E DISCUSSÃO}

A flutuação de Anastrepha spp., medida pelas contagens das moscas-das-frutas capturadas entre setembro a fevereiro, foi significativamente menor em 2003 em relação a 2002 e 2004, respectivamente, em torno de 4,8 a 3,6 vezes (Figura 1). Essa diferença na captura de moscas-das-frutas verificada entre os anos pode estar relacionada com hospedeiros nativos na mata, resquício de Mata Atlântica, que delimita o pomar, pois as moscasdas-frutas não são residentes do pomar (Sugayama \& Malavasi, 2000). O início das capturas coincidiu com a colheita do pêssego 'Coral II' na Lapa. A captura de moscas-das-frutas em pessegueiro, na Lapa, concentrou-se a partir da segunda quinzena de novembro até o final de janeiro, nos três anos do experimento.
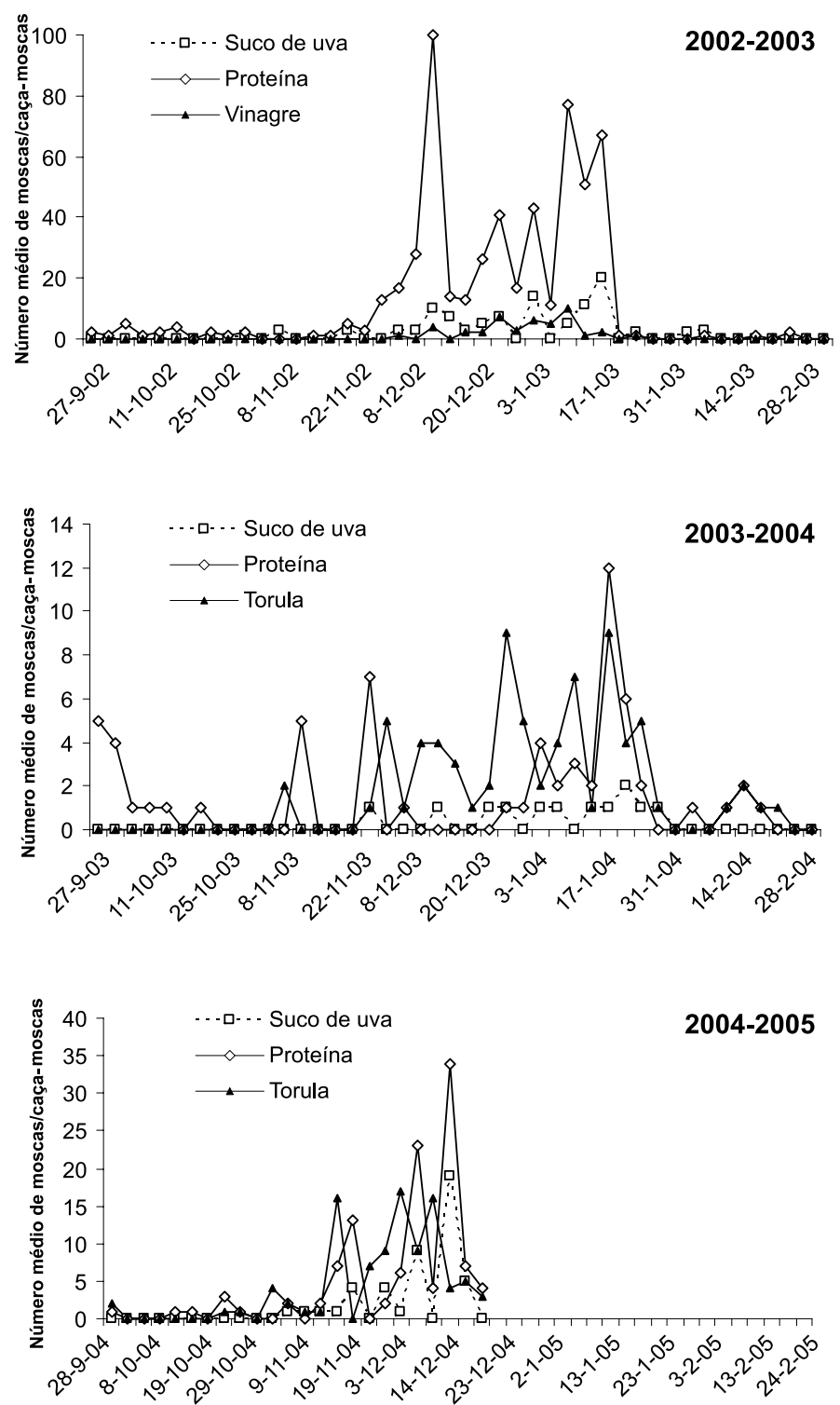

FIGURA 1 - Número médio de moscas Anastrepha spp. por caçamoscas em três atrativos alimentares em pomar de pessegueiro, em três anos, Lapa-Paraná.

Em 2002, a proteína foi significativamente mais atrativa, chegando a capturar mais de 100 moscas-das-frutas no intervalo de quatro dias (6-12 a 10-12-2002). O vinagre foi o menos atrativo, sendo por isso substituído nos anos posteriores (Tabela 1). Em 2003 e 2004, a proteína e a torula foram igualmente eficientes na atração de Anastrepha spp. Os resultados obtidos com os atrativos à base de proteína estão de acordo com Mendonça et al. (2003), que observaram maior captura com esses atrativos.

A atração exercida pelos atrativos de proteína permitiu que as capturas de moscas-das-frutas ocorressem desde o início do monitoramento, no mês de outubro, enquanto o suco de uva capturou a partir do final de outubro, em 2002, e ao final de novembro, em 2003 e 2004. Essa maior atratividade para os derivados de proteína pode estar relacionada com a necessidade dos adultos em ingerirem aminoácidos para a produção de óvulos 
TABELA 1 - Número médio de adultos de Anastrepha spp. por caça-moscas em pomar de pessegueiro usando atrativos alimentares, em três anos de avaliação, Lapa-Paraná.

\begin{tabular}{lccc}
\hline Atrativo & \multicolumn{3}{c}{ Ano de captura } \\
\cline { 2 - 4 } alimentar & 2002 & 2003 & 2004 \\
\hline Suco de uva & $2,1 \pm 4,29 \mathrm{aB}$ & $0,2 \pm 0,5 \mathrm{aA}$ & $1,9 \pm 4,25 \mathrm{aB}$ \\
Proteína & $11,1 \pm 22,81 \mathrm{bB}$ & $1,2 \pm 2,44 \mathrm{bA}$ & $4,6 \pm 8,16 \mathrm{bAB}$ \\
Vinagre & $0,88 \pm 2,19 \mathrm{a}$ & - & - \\
Torula & - & $1,4 \pm 2,45 \mathrm{bA}$ & $4,1 \pm 5,48 \mathrm{bB}$ \\
\hline
\end{tabular}

Médias originais. Para análise estatística, os dados foram transformados em $(\mathrm{x}+0,5)^{0,5}$ Médias seguidas de mesma letra não diferem entre si, minúscula na coluna e maiúscula na linha, pelo teste de Tukey $(\mathrm{p}<0,05)$,

(Zucoloto, 2000), sendo que as fêmeas que ingerem proteínas são mais receptivas à cópula (Cangussu \& Zucoloto, 1997).

Embora tenha se observado uma captura antecipada de Anastrepha com atrativos à base de proteína, isso não quer dizer que é indicativo para recomendar pulverizações com inseticidas em cobertura desde as primeiras ocorrências, visto que, em outubro, os frutos estão verdes e menos suscetíveis ao dano, como ocorre em citros (Nascimento \& Carvalho, 2000). Com isso, outros estudos deverão ser realizados para se determinar o nível de controle quando atrativos à base de proteína são empregados no monitoramento em pessegueiro e a influência desse resultado sobre o manejo de moscas-das-frutas.

\section{CONCLUSÃO}

Concluiu-se que os atrativos alimentares à base de proteína são mais eficientes do que o suco de uva e o vinagre para a captura de Anastrepha spp. em frascos caça-moscas McPhail, na região da Lapa-PR.

\section{AGRADECIMENTOS}

Agradecemos ao Conselho Nacional de Pesquisa Científica e ao Ministério da Agricultura, Pecuária e Abastecimento, pelo financiamento deste estudo.

\section{REFERÊNCIAS}

CANGUSSU, J.A.; ZUCOLOTO, F.S. Effect of protein sources on fecundity, food acceptance, and sexual choice by Ceratitis capitata (Diptera: Tephritidae). Revista Brasileira de Biologia, São Carlos, v.57, p. 611-618., 1997.

FACHINELLO, J.C.; COUTINHO, E.F.; MARODIN, G.A.B.; BOTTON, M.; MAY DE MIO, L.L. Normas técnicas e documentos de acompanhamento da produção integrada de pêssego. Pelotas: Universidade Federal de Pelotas, Faculdade de Agronomia Eliseu Maciel, 2003. 92p.

HICKEL, E.R. Pragas do pessegueiro e da ameixeira e seu controle no Estado de Santa Catarina. Florianópolis: Epagri, 1993.45p. (Boletim Técnico, 66).
KOVALESKI,A.; SUGAYAMA, R.I.;URAMOTO, K.; MALAVASI, A. Moscas-das-frutas nos estados brasileiros. Rio Grande do Sul. In: MALAVASI, A.;ZUCCHI, R.A. (Ed.). Moscas-dasfrutas de importância econômica no Brasil: conhecimento básico e aplicado. Ribeirão Preto: Holos, 2000. 327p.

MENDONÇA, M.C.; NASCIMENTO, A.S.; MELO, A.S. Eficiência da atratividade da isca fotoativa para moscas-das-frutas. Revista Ciência Agronômica, Fortaleza, v.32, p.147-152, 2003.

MONTEIRO, L.B.; HICKEL, E. Pragas de importância econômica em fruteiras de caroço. In. MONTEIRO, L.B.; MAY DE MIO, L.L.; SERRAT, B.M.; MOTTA, A.C.V.; CUQUEL, F.L. Fruteiras de caroço: uma visão ecológica. Curitiba: Universidade Federal do Paraná, 309p.

NASCIMENTO, A.S.; CARVALHO, R. da S.; MALAVASI, A. Monitoramento populacional. In: MALAVASI, A. ZUCCHI, R.A. (Ed.) Moscas-das-frutas de importância econômica no Brasil: conhecimento básico e aplicado. Ribeirão Preto: Holos, 2000. 327p.

NASCIMENTO, A.S.; CARVALHO, R.da; S. Manejo Integrado de Moscas-das-frutas. In: MALAVASI, A.; ZUCCHI, R.A. (Ed.). Moscas-das-frutas de importância econômica no Brasil: conhecimento básico e aplicado, Ribeirão Preto: Holos, 2000. $327 \mathrm{p}$.

SALLES, L.A.B. Bioecologia e controle da moscas-das-frutas (Anastrepha spp.) Sul-americana. Pelotas: Embrapa-CPACT, 1993.58p.

SALLES, L.A.B. Moscas das frutas (Anastrepha spp.): bioecologia e controle. Pelotas: Embrapa, 1991. 16 p. (Documento, 41).

SUGAYAMA, R.L.; MALAVASI, A. Ecologia comportamental. In: A. MALAVASI, A.; ZUCCHI, R.A. (Ed.), Moscas-das-frutas de importância econômica no Brasil: conhecimento básico e aplicado. Ribeirão Preto: Holos, 2000. 327p.

ZUCCHI, R.A. Taxonomia. In: MALAVASI, A.; ZUCCHI, R.A. (Ed.). Moscas-das-frutas de importância econômica no Brasil: conhecimento básico e aplicado. Ribeirão Preto: Holos, 2000. 327p.

ZUCOLOTO, F.S. Alimentação e nutrição de moscas-das-frutas. In: MALAVASI, A.; ZUCCHI, R.A. (Ed.). Moscas-das-frutas de importância econômica no Brasil: conhecimento básico e aplicado. Ribeirão Preto: Holos, 2000. 327p. 